\title{
Loudly sing cuckoo: more-than-human seasonalities in Britain
}

Andrew Whitehouse

\section{Abstract}

This article explores seasonality through the lens of British relations with other beings. Drawing on discussions of temporality and seasonality by Ingold, Harris and Krause and extending them in the light of developments in more-than-human anthropology, the qualities of different sorts of seasonal, more-than-human relations are explored. Haraway's emphasis on an intimate 'being with' other species is used to consider close seasonal relations that draw beings together in shared tasks. However, in modern societies such as Britain, where lives are lived as much indoors as out, less intimate seasonal relations can still carry great significance. These relations are explored using Latimer's concept of 'being alongside'. This distinction is expanded upon by comparing narratives of listening to birds in Britain with ethnographic examples from non-European societies where people procure their own subsistence and lead seasonal lives closely enmeshed with plants and animals. Similar relations are examined between farmers and other beings on the Scottish island of Islay, where wild geese and domestic livestock graze the same pastures and where government conservation schemes require the mowing of grass at specific times to foster the breeding success of rare corncrakes. Here 'being with' other species is complicated by seemingly detached bureaucratic government schemes, which nevertheless are drawn into the seasonal taskscape by the effects they have on humans and nonhumans alike. Finally, newer seasonal relations with nonhumans that emerge through the use of technologies such as radio-tracking and websites are considered. These render global ecologies of more-than-human seasonality visible in relations of remote witnessing. Seasonality is thus explored as a means to consider the specific relations of place, the contradictions and tensions between being-in-the-world and bureaucratic schemes, and the fragility of the ties that bind weather, wildlife and nation in a time of rapid environmental change.

\section{Keywords}

seasonality, more-than-human, birds, Britain, being alongside, taskscape, Islay 
Summer is a-coming in

Loudly sing cuckoo

Groweth seed and bloweth mead

and springs the wood anew

Sing cuckoo!

So begins a famous Medieval English round, one of the earliest known songs in English (McCarthy, 2009). Probably written in the $13^{\text {th }}$ century, the song exemplifies how connections emerge between seasons and the activities of other-than-human beings. Seasonal rhythms have long been heralded by certain birds beginning to sing or returning from migration. That these connections are deep-rooted is perhaps inevitable and far from unique to Britain. What is less clear is whether they remain significant in a modern Britain in which economic relations with other beings, such as through agriculture, are distant and indirect for many and in which 'seasons' are as likely to be experienced as TV box sets as in the outdoors. My aim is to explore more-than-human seasonalities in contemporary Britain, examine their particularities and consider the role of other beings in temporal humanenvironment relations. I do this through varied examples including bird enthusiasts, Scottish farmers and scientific research into bird migration. I focus particularly on relations with birds but various other organisms, both wild and domestic, are bound up in these temporal goings-on. Birds, however, have a long history of association with seasonality in Britain, perhaps because of their prominence both by sound and sight and their seasonal movements. As such they provide a widely appreciated focal point for many people's sense of seasonality.

In exploring seasonality, I take inspiration from two research projects. The first was a period of fieldwork on the island of Islay in western Scotland between 1999 and 2000 that examined relations between nature conservation and farming. I also draw on respondents to the Listening to Birds project, ${ }^{1}$ which ran from 2007 to 2009 and took an anthropological approach to understanding people's relations with birds through sound. People were invited to send accounts of their own listening practices via the project website and many of these accounts touched on the seasonal associations of bird sounds. For example, Catherine from Woking wrote: "I always know that spring has arrived when I hear my first chiffchaff singing its unmistakable two-note song." Andrew from Sussex noted, "The one [bird] I always listen

\footnotetext{
${ }^{1}$ This research was funded by a grant from the Arts and Humanities Research Council, grant number $\mathrm{AH} / \mathrm{E} 009573 / 1$
} 
out for is swifts. They don't make a nice noise but I always associate their arrival with the beginning of summer." A respondent from Scotland commented, "The sound of geese coming in from the north herald for me the beginning of winter." Here I examine what sorts of relations are involved in accounts like these. More generally, I consider how people in contemporary Britain experience seasonal change in relation to the activities of other-thanhuman beings, given that for most these relations are no longer central to their economic practices. This in turn raises broader questions about how seasonal change might be reconsidered as an example of more-than-human relations. My approach to seasonality is thus situated in a context of recent developments in more-than-human social science developed by theorists from anthropology, sociology, geography and philosophy (Haraway 2003; 2008; Kirksey \& Helmreich, 2010; Kohn, 2013; Latimer, 2013; Ogden et al., 2013; Whatmore, 2006). These approaches take human and nonhuman lives to be inextricably bound in ways that transcend dualisms such as nature and society. This distinguishes my approach from earlier analyses of seasons (Evans-Pritchard, 1940; Mauss, 1979; Young, 1988) that took the distinction of nature and society as axiomatic, aligning it more closely with recent work on temporality and seasonality (Harris, 1998; Ingold, 2000; Krause, 2013) that considers seasons as emergent from dwelling rather than as chronological periods imposed upon natural cycles.

To explore these associations of seasonality and wider environmental relations, I first examine the aforementioned anthropological and sociological approaches to temporality and seasonality and consider how these could be extended in light of developments in more-thanhuman social science. I then discuss the qualities of the different sorts of seasonal, morethan-human relations exemplified in my research. Many recent approaches to cross-species relations draw on Haraway $(2003 ; 2008)$ to emphasise an intimate 'being with'. Here, however, I also consider relations that may be less intimate but still carry great significance, leading me to consider Latimer's (2013) concept of 'being alongside'. I highlight this distinction by comparing responses from the Listening to Birds project with ethnographic examples from non-European societies. I then investigate the close and complex seasonal relations between farmers and other beings in Islay as a form of 'being with'. I complicate these relations by considering how detached bureaucratic government schemes are drawn into these more-than-human seasonalities. I conclude by considering newer seasonal relations with nonhumans that emerge through technologies such as radio-tracking and websites. These enable many people to follow the global ecologies of more-than-human seasonality in 
relations I describe as remote witnessing. In discussing these examples, my intention is not to cover a representative sample of different types of more-than-human seasonalities in Britain but to discuss a small number of cases that exemplify the more general relations involved.

\section{Seasonal approaches beyond nature and society}

Despite its subtle methodological prominence in observing annual social and economic cycles, seasonality has rarely been explicitly theorised by anthropologists. In the instances where this has happened, two tendencies stand out. The first is the separation of seasonal activity into natural and social cycles. This is most clearly exemplified in the classic works of Mauss (1979) and Evans-Pritchard (1940) but also by the sociologist Michael Young (1988), who distinguishes natural cycles, both ecological and bodily, from chronological time imposed by society and administered through clocks, timetables and calendars. The second tendency is a contrast between approaches that examine the categorisation of cyclical time into different units and those that view seasonal change as generated rhythmically through the activities of humans and nonhumans in a shared life-world (Harris, 1998; Ingold, 2000; Krause, 2013). This last approach is more precisely about seasonality than seasons and draws particularly upon Ingold's conceptualisation of temporality. These tendencies point towards tensions between experience and structure that emerge through British seasonalities and that influence the ways that other organisms are drawn into meaningful perceptions of seasonal change. These tensions and theorisations influence my own approach, so require further elaboration.

In his efforts to understand the influence of the 'material substratum' on the organisation of society, Marcel Mauss ([1940]1979) was attempting to go beyond the assumption that seasons simply provided environmental constraints; instead, he argued that they were bound up in the current of social life (Harris, 1998). Though the influence of more-than-human relations and material factors are acknowledged as profound by Mauss, he approaches these relations from the premise that they inherently contrast with relations amongst humans. As such, seasonal patterns are, for Mauss, about the articulation of nature and society and their variations through the year. Evans-Pritchard's took a similar approach in The Nuer (1940). He divided Nuer time into cycles organised in terms of nonhuman relations, termed 'oecological time', and activities organised by social relations, termed 'structural time'. Oecological time was cyclical and associated with seasons and lunar phases. Structural time 
was more closely associated with longer durations, for example periods in a human lifespan. Seasonal rains were more significant than any astronomical cycles in influencing Nuer timereckoning, which divided the year into two periods called mai and tot. These were not exact lengths of time but "rather vague conceptualisations of changes in oecological relations and social activities which pass imperceptibly from one state to another" (ibid. p.98). Mai and tot were thus associated with activities and conditions rather than specific blocks of time and "since the words tot and mai are not pure units of time-reckoning but stand for the cluster of social activities characteristic of the height of the drought and of the height of the rains, one may hear a Nuer saying that he is going to 'tot' or 'mai' in a certain place" (ibid. p.99). In other words, oecological time was not simply about the rhythms of nature but about the interaction of people with the ever changing conditions of the landscape. The 'coordination of events' was not simply to do with astronomical time but how time emerges through the activities of Nuer, their cattle and their wider ecological relations.

Despite being grounded in the separation of society and nature, one can see in EvansPritchard's account hints of more recent relational approaches to time in which seasonality is understood as rhythmic and emergent rather than as a category of thought. These ideas are articulated by Ingold (2000) for whom temporality is immanent in the passage of events rather than transcendent of them. Ingold extends his approach to temporality through the concept of the taskscape (ibid. pp.194-200): the array of activities that carry forward life. Taskscape emerges through dwelling: people's being in the world and their consequent engagement with their surroundings. Ingold explains the taskscape and its relation to temporality by drawing an analogy with time as it emerges in music (ibid. pp.196-198). When musicians play they need to keep in time and the music that emerges also has a time. Time in music thus arises from the attentive activities of musicians rather than being independent of their playing. It is in this sense that temporality is social. It involves attending to others and their activities, including those of nonhumans, and resonating with them (ibid. p.196). Temporality is to taskscape what rhythm is to playing music. Many practical and economic tasks involve attending to other beings, something readily apparent in subsistence activities but less clear in the quotidian practices of modern, post-industrial societies. In the latter, the taskscape may be less directly concerned with nonhumans and the seasonal changes they are bound up with. This is a contrast I return to later. 
Following Ingold, Harris (1998) has argued that seasonality and temporality are aspects not so much of nature or culture, but of dwelling and the sort of sharp distinction earlier authors such as Mauss and Evans-Pritchard made between ecological and social cycles of time is irrelevant. Harris also extends the distinctly phenomenological emphasis Ingold places on the rhythmic emergence of seasonality in his study of life in the Amazon flood plain, where people "continually '[attend] to'... the rise and fall of the river, fish migrations, animal movements, soil hardening, plant growth and decay, the winds, rains and so forth, and [adjust] their own movements to this on-going perceptual monitoring so as to achieve a 'resonance' with the fluctuations of the environment" (1998 p.66).

Seasonality might thus be likened to a dance in which humans, animals, plants, rivers, soils and weather are bound together, rather than being a response to chronological periodicity. In so doing, Harris avoids the problem that both Mauss and Evans-Pritchard had in deciding whether time is ecologically determined or socially constructed, and the contradiction that follows from this that humans construct the world prior to inhabiting it but are then in turn determined by that world. By adopting an emphasis on dwelling that avoids sharp separations between ecological and social processes, Harris argues that these problems 'simply disappear' (1998 p.67).

A similarly rhythmic approach to seasonality is taken by Franz Krause (2013) in his work along the Kemi River in northern Finland. In doing so he argues against the classificatory approach of Orlove (2003) that focuses on the naming of seasons as recurring blocks of time characterised by specific phenomena, thus grouping natural phenomena together with culturally constructed categories for seasons. Krause, conversely, argues that Kemi River dwellers draw on seasonal categories to point towards the ongoing interplay they encounter through their practical involvement with the world rather than to conceptually order detached material phenomena into discrete periods. Just as Rodríguez-Giralt et al (2014) argue in relation to disasters, seasons for Krause are not discretely bounded events in space and time but relational unfoldings of humans, nonhumans, institutions and physical processes.

Krause's work on seasonality is unusual in that it focuses on a modern society that includes hydropower stations and tarmac roads as well as boats, fish and snowshoes. He emphasises the resonance of humans, other beings and ecological cycles as seasonality emerges but others have argued that in modern societies a stark dissonance has enveloped seasonality. 
Harrison (2004), for example, explores Seasonal Affective Disorder, arguing that this is a culture-bound disease arising from the disjuncture between natural and social cycles in modern societies. We thus seem to be back with dualisms rather than the relational emergence of seasons described by Krause. Indeed, the ruptures that exist between the outdoor world of ecological seasons and the indoor world where chronological time assumes prominence seem to 'fit' rather readily with those dichotomies but, I argue, this does not have to be understood as a disarticulation between human society and natural cycles.

These concerns were explored in the sociologist Michael Young's (1988) critique of modern temporal habits, The Metronomic Society. Young's account of the disjuncture of natural rhythms and human timetables draws together social and biological research to understand the effects of modern lifestyles that appear to distance humans from seasonal and meteorological change. Modern people mostly inhabit controlled, indoor environments that are centrally-heated and bathed in artificial light. Such lives only involve irregular and insubstantial engagements with the outdoor world of weather and nonhumans. The effect of these developments on bodily circadian rhythms and photoperiodism is, according to Young, a profound problem only added to by the metronomic societal demands of chronology. Rather than attending to subtle daily and annual changes in light and the responses of animals and plants to those changes, society demands that humans respond to the artificial units of time encapsulated in the clock or the calendrical date. This metronomic society, for Young, has trounced nature in determining the habits of its people. The linear time of the factory and the office has obscured the cyclical rhythms of body and ecosystem.

Although Young pursued his argument in terms of a battle between society and nature, his points about the problems of a predominantly indoor, chronologically-influenced life are still pertinent. How, though, can this issue be approached from a position that does not assume a separation of society and nature? If we return to Ingold's discussion of the taskscape and take it indoors to the office or factory, we can see that the clock and the calendar, which for Young are instrumental in separating humans from natural cycles, are also a part of the environment. Their influence only arises when worked at and in relation to specific tasks; people need to attend to the clock for it to have its effects. The indoors is an environment with its own specific tasks that engender distinctive temporalities. If the task at hand is watching TV then the clock and schedule will play more significant roles than the sun. This is not to say that being indoors is unrelated to seasonality. The movement between indoors 
and outdoors can be seasonally influenced too. Sitting by a roaring fireplace, or putting on the central heating are as much seasonal winter activities as walking through the snow. The sounds of birds are also quite readily able to penetrate indoors, bringing their own more-thanhuman temporalities to someone lying in bed or watching TV.

From this discussion of social science approaches to the seasonal, I take forward three general points:

1. The conceptual distinction between social and material/natural cycles is not relevant. They are united through our being in the world and are bound together through the activities of beings both human and nonhuman: the taskscapes through which seasons are made. 'Nature' and other categories can still be important as means of pointing towards experience but they do not determine how experience is ordered.

2. Being outdoors and indoors are both forms of environmental relations that are bound up in seasonal taskscapes. The influence of seasonality is less apparent in societies where more time is spent indoors and 'metronomic society' has reduced the significance of outdoor seasonality on human activities. This distinction is not an argument suggesting that some peoples live closer to nature than others but that the predominance of indoor and outdoor living influences the sorts of tasks and environmental relations that prevail in the experiences of different peoples.

3. The tension in industrial societies between seasonality and chronological time is acute. Manifestations of chronological time are not independent from environmental relations but are less determined by the wider activities and cycles of seasonality. They are still elements of the taskscape that have to be worked at in order to have significance.

I now draw on these initial theoretical conclusions to consider the sorts of more-than-human relations encountered in a modern society such as Britain, where tasks are less often bound up with other beings than in societies where most people procure their own subsistence. Later, I consider the emergence of seasons in farming, something quite directly associated with relations between human and nonhuman beings but also influenced by the apparently societal impingements of bureaucracy and policy. 


\section{More-than-human seasonalities}

The widespread diminishment or obfuscation of ecological and seasonal relations in industrial society has generated a range of concerns and responses. For many, close ties to nonhumans bound up in the material cycles of the world have been a way of revealing and reimposing the sorts of bonds that a more indoor, chronologically-influenced life obscures. Often this takes the form of leisure activities such as gardening or birding. For birders seasonality is constantly unfolding with the dynamic presence of the birds they seek. Seasonal migrations provide a particular focal point, with birders attending to the arrival, departure and passage of different species and also the appearance of unusual species that these movements sometimes provoke.

Social scientists have also sought out and revealed obscured relations with other beings by reconsidering the place of nonhumans in social life. In recent years these attempts have proliferated in what has variously been called 'the anthropology of life' (Kohn, 2013), multispecies ethnography (Kirksey \& Helmreich, 2010; Ogden et al, 2013) or more-thanhuman approaches (Whatmore, 2006). Sociologists and others have argued against human exceptionalist tendencies that place nonhumans outside of society (Peggs, 2013; Cudworth, 2015), while Hurn (2012 pp.1-4) argues that anthropological tendencies to ignore nonhumans or to treat them as mere objects must be reflexively overcome in order to properly understand what it means to be human. These developments have inevitably been cross-disciplinary and promiscuous in their emergence, marrying anthropology with sociology, philosophy, cultural geography, art, history, and biology. They have in common a concern to avoid severing the lines connecting humans and nonhumans with the sharp knife of the society-nature dualism, instead tracing these lines as they entangle different beings and life-worlds.

Both 'beings' and 'being with' have assumed prominence in these new approaches. For Haraway $(2003 ; 2008)$, other species are good to be with and indeed this being with is essential to being human, not least because of the rich ecosystem of microbial life that sustains and makes up the human body. Haraway re-orders close and intimate relations between human and nonhuman to allow for differences that are not grounded in human exceptionalism. More recently the sociologist Joanna Latimer has adapted Haraway's approach to consider relations in which ties between humans and other beings are more 
distant and partial, but still meaningful. Latimer argues for an attention to being alongside rather than being with, claiming that:

It is this attaching and detaching to different others, partially connecting and partially disconnecting, that produces a form of dwelling amidst different kinds that I am calling being alongside (2013: 81).

This sense of partial connection is, I contend, useful for thinking about the seasonal morethan-human relations that arise in modern Britain. This is not to say that these relations are insignificant but that they are interesting, aesthetically pleasing and emotionally moving rather than life-altering signals that must be attended to if one is to survive and prosper. More-than-human seasonalities might thus be distinguished in terms of those that involve being with nonhumans and those that involve being alongside. A glance at more-than-human seasonalities in societies where life for most is bound up in close participation with nonhumans through subsistence will clarify this distinction.

For predominantly agricultural or hunting and gathering societies, seasonal activities are inherently bound with other beings. The Kaluli of New Guinea know when the season of $t \varepsilon n$ has begun when they hear a rainbow bee-eater (Feld, 1990: 61). The Nage of Flores know that the rainy season starts when they hear channel-billed cuckoos and common koels calling, and they soon start planting their crops of maize in response (Forth, 2004: 180). Levin describes Tuvan responses to the coming of spring thus:

The migration to the spring camp... takes place when the food supply in the winter camp is close to being exhausted, but before new growth has appeared there - typically as the snows melt in late April or early May. Herders tried to move as early as possible in order to keep herds from eating new growth that will be needed the following winter... The singing of the bird that Tuvans call baa-saryg, literally, 'yellowbreasted,' indicates that it is safe to plant grain. Sowing and planting have to take place before the sound of the cuckoo bird signals the end of the moist winds... With the end of that work, it becomes necessary to migrate quickly to the summer pasturage in order to fatten the livestock, particularly young animals, on fresh grasses (2006 p.142). 
What is striking here is not just that Tuvans attend to their domestic animals and to wild animals and plants but that their own activities are a direct response to the activities of nonhumans. The beginning and end of sowing is signalled not by dates on a calendar but by the singing of two migratory birds. The movement of Tuvans around their lands is always in relation to the needs, both short- and long-term, of their herds and the growth of the grasses on which they feed. Tuvans attend to the variable sounding of the 'cuckoo clock' rather than to the chronological clock. Cuckoos are not just good to hear but good to act on.

As I describe below, farmers in Britain also attend to what nonhumans are doing, though it is perhaps less common for them to act in response to species that are not directly bound up in their own productive activities. But their seasonalities, like the Tuvans, involve being with nonhumans in ways that are close and directly responsive. For others in Britain, temporal relations with nonhumans are more partial, involving being alongside. Michael Young was keen for people to take more notice of the temporalities of other beings, describing a typical urban British scene thus:

While at one minute after six with bent heads the clerks shuffle homeward down into the tube station, above their heads, if only they would look up, the starlings are excitably wheeling in the sky and the swifts darting about in the fading light to remind them of what was and could be. The swifts are not killing time or being killed by it. They are taking advantage of a dusk which is not yet a night (1988: 258).

Sometimes people do look up, and this can be profoundly important even if it is just about feeling that they have a common life alongside birds rather than bound up with them. Those starlings and swifts are not likely to be a signal for specific human actions but Young is arguing that they could still provide a sense of resonance through the recognition of life going on in a common world. I disagree with Young, however, in explaining this sort of resonance as a correspondence between the social world of humans and the cycles of nature. Instead, the form of resonance I call 'being alongside' is premised on humans noticing their sharing of the world with nonhumans and the temporalities that sometimes draw all these beings together. The tasks that humans and nonhumans are conducting in this instance are not directly shared or co-responsive but are occurring in the same shared world. 
As Young implies, noticing this sharing is not universal but there are important aspects of shared experience that, I argue, are central to peculiarly British forms of more-than-human seasonality that develop from assumptions about British geography. Britain is noted as a nation of nature lovers and also as obsessed with the weather (Harley, 2003). The seasonal goings-on of other beings are thus widely noticed but in ways that emphasise common, shared experiences. Following from this, powerful links can be made between nature and nation. In Britain these links emerge in distinctive ways for two reasons: its status as an island nation and the relative similarity of wildlife and weather throughout much of the country. The common flora and fauna in Aberdeen mostly correspond to those in Aberystwyth and Arundel. Those places also enjoy a temperate, maritime climate that produces seasonal changes that, whilst inherently unpredictable, are also not consistently or substantially different. These seasonal and ecological similarities facilitate the potential for people living in many parts of Britain to share closely comparable seasonal encounters with other beings. Assumptions of the potential for a shared national experience of more-thanhuman seasonality are essential to the success of the popular BBC television series Springwatch. Although the series celebrates distinctive wildlife found in particular places, it focuses far more on species familiar to viewers across the nation. It also assumes that as spring emerges in one part of Britain, it is emerging in roughly similar ways in other parts. If a programme like Springwatch was made in, for example, the United States it would be far harder to develop a shared national sense of more-than-human seasonality because these common experiences would be impossible to sustain in such a climatically and ecologically diverse nation.

While Britain provokes a strong sense of shared seasonality, its status as an island nation also promotes a sense of distinctiveness in terms of the species found there, as well as those not found there. Species are deemed 'native' by biologists because they arrived before the closure of the continental land bridge, after which Britain became a much harder place to 'invade'. This correspondence between nature and the island nation rose to prominence during and after the Second World War, when Britain's vulnerability to aerial attack was countered through the development of radar and familiar wildlife became the distinctive 'heritage we're fighting for' (Davis, 2011; Macdonald, 2002). Narratives of the seasonal arrival of migratory birds thus tend to be told in the sense of 'our' birds returning home from travels overseas. As swallows arrive from wintering in Africa, they are then drawn into the making of a British summer, something that emerges through the activities of humans and 
other species and that TV shows at least presume to be a shared national experience. The sorts of personal experiences I now go on to describe are thus readily drawn into larger narratives of nature and nation.

\section{Making seasons and resonance}

'One swallow doesn't make a summer', the saying goes. But lots of swallows do help to make a summer, along with the insects they feed on, the plants that grow and sustain the insects and the warmth and light that enable plants to photosynthesize. This throng of interactivity is about the making of seasons, not simply their content. Humans in modern Britain take a less active role in this making, at least when they are indoors. This is not to say that being indoors precludes an active role in seasonality. Even swallows find their way in through porous walls to nest in barns and sheds, secure from predators, rain and wind. Swallows, it could be argued, also help make the winter by their absence. If we consider seasons to emerge relationally, seasonal change is as much about what leaves as what arrives. Dry seasons are made as much by the absence of rain as wet seasons are made by its presence.

For humans who live and work predominantly indoors, their own role in making seasons can be less apparent. This is not to say they have no effects on the outdoor ongoing-ness of life but that those effects are less direct or local. The making of seasons is not simply about the astronomical movements that alter the duration of daylight. As the historical geographer Kenneth Olwig notes:

To the farmer... it is not particularly helpful to calculate the spring growing season as beginning on 21 March... Natural phenomena such as the sprouting of leaves are more realistic indicators of spring because seasonal transition involves a highly irregular, complex process of interrelated climatic, geologic, floral, faunal and social change, and the ability to read all the signs of this change correctly can spell agricultural success or failure (Olwig, 2005: 260).

Making seasons is about a whole complex of doings that are responded to and rendered meaningful to others in the meshwork (Ingold, 2011; Rodríguez-Giralt et al., 2014; Whitehouse, 2015). The sprouting of leaves heralds the spring to the farmer, who then acts to 
plant his own crops. When people notice seasonal heralds their attention is being drawn to rhythmic shifts suggesting new activities and possibilities for themselves, even when these activities do not directly relate to the herald itself. Hearing the first cuckoo of spring might provoke thoughts of evening walks as the days draw out towards summer. This is a less strong kind of signal than Tuvans understand when they hear a cuckoo; it is a suggestion rather than a compulsion. For people who live predominantly indoors and do not procure their own subsistence directly, seasonal change brings with it an array of possibilities to act. For Tuvans who rely on their crops and animals, seasonal heralds provoke quite specific responses towards the making of the season.

What is more likely to follow for British people is a sense of being alongside birds. Following from this understanding, many respondents to the Listening to Birds project expressed feelings of well-being when hearing birds and this seems most apparent when people's lives also resonate with these rhythms (see Ingold, 2000 p.196), as these experiences recounted by Rob from Droitwich illustrate:

As a farmer I'm up well before dawn at this time of year but even now there are birds singing in the morning... As we move into spring I'm lucky enough to hear the dawn chorus every day and it does give me a real lift. Lambing time can be magical when you see new born lambs taking their first steps to a sometimes deafening suite of blackcaps, robins, chiffchaffs, willow warblers and the rest. If you can't appreciate that then there's something seriously wrong with you.

Despite being a farmer, Rob's attention to the birds he hears is primarily in terms of the way they make him feel rather than how they directly affect his own activity: a more intimate being with his livestock. By attending to the activities of birds as they go about their lives he is given 'a real lift'. This lift, I argue, stems from a sense of resonance that comes from this 'sympathetic attention' (Harris, 1998 p.79) to the activities of other beings in a shared world. Resonance is integral to how people idealise experience and how they want relations with places to be, as this quite typical account by Barbara from Durham exemplifies: 
The Robin [is] my favourite bird. It just conjures up autumn and winter and its song seems to carry on the cold air and it makes me feel all warm and cosy inside. Always has. Whenever I hear [starlings] it reminds me of spring days on the way. When the sun is getting a little warmer but it can still be a chilly day and you know the longer brighter days are on the way. My third [experience] is the blackbird especially at dusk on a sultry evening after a hot sunny day, when everything is still. No wind, very warm. About 10 p.m. at night, still light and it reminds me of being little again. My fourth and final one has very special memories for me. Me and my Dad, who is now longer with me, used to go for long walks on sunny summer afternoons with our dog when I was very little to fields and wastelands and skylarks used to fill the sky. My Dad told me their names and I never forgot it. Even now when I hear one I say 'I can hear a skylark' and it takes me back to being with my Dad when I was a little girl.

For Barbara, certain bird sounds 'conjure up' memories of similar times and seasons and of other people and animals that she shared those occasions with. Hearing the sound is contextualised and deepened by feeling the air and sensing the light. Listening to birds, then, is a multi-sensory aesthetic experience of the whole landscape and its ongoing seasonality. As weather and seasons change, as daylight comes and goes, as rivers rise and fall, so plants grow and die, so animals arrive, breed, migrate, roost and sing. Our own activities are related to and even stimulated by those of nonhumans as they go about their lives. Even when those relations are not direct, the resonance that comes from being alongside other organisms provides a sense of inhabiting a shared world in which seasons are being made by a host of other living creatures. Sometimes, however, the arrival and presence of other beings can provoke more anxious or politically fraught feelings.

\section{Wild, domestic and bureaucratic seasonalities}

Sometime in the first half of October, the people of Islay awake to find the fields and marshes of their Scottish island home smothered with a voluble covering of geese. The geese arrive en masse like a fresh falling of snow and proceed to spend six months grazing their way through bioengineered rye grass fields, rough marshy edges and stubble. Their migration takes them from the tundra of Greenland, via Iceland to the mild, Atlantic shores of western Scotland and Ireland. This wintering mainly involves two kinds of geese: the stocky, black and white barnacle geese and the taller, brownish Greenland white-fronted geese. The 
farmers would prefer that the grass is grazed by lambs born in spring, but the favoured early bite is swiftly taken by the throng of geese before the lambs are on their feet. The geese also graze the silage fields, where summer growth is stored to provide winter feed for cattle and sheep. It was even suggested to me that the geese had increased in number in Islay as a result of farmers switching to growing grass for silage. The geese, I was told, prefer the shorter grass crops that silage cutting leaves for the winter.

The burgeoning numbers of geese have emerged alongside other agricultural developments. Over recent decades, Islay farmers have switched to stocking large, 'continental' breeds of livestock that produce more meat than hardy native breeds (Whitehouse 2004; 2012). Like humans, the new breeds have retreated indoors because they struggle to find adequate food during the winter and so have to be in-wintered and fed on silage and supplements. One farmer explained that, although the early bite in spring is important for livestock, losing it to geese created a further problem in that cattle had to in-winter for longer, driving costs for feed up. Goose grazing also meant that silage would have to be made later. By the time a second cut was taken it was more likely to be lost due to wetter weather. He mentioned research that had been done showing that geese also bring in weed seeds from areas of rough pasture, deteriorating the sward.

The farming landscape of Islay and its seasonal cycles are thus influenced not just by the farmer and his domestic animals and crops but the wild and recalcitrant presence of geese that spend their summer in the tundra of Greenland. This is not to say that geese provide no income to the farmer. Measures to protect them mean that compensation schemes have been developed by Scottish Natural Heritage (SNH), the government body concerned with conservation in Scotland (Whitehouse, 2004; 2009). Farmers have received payments that attempt, at least on the face of it, to compensate their losses from the geese but given that the geese would graze their fields come what may they can seem like a seasonal source of income, albeit from the wrong source as farmers see it. The disruption to the spring and summer grazing of livestock compounds farmers' concerns about the ongoing viability of their livelihood. Sometimes even the compensation payments for geese fail to raise the mood, particularly when individual farmers think they receive a raw deal. As one told me:

The fact of the matter is, if we were getting the right money it still wouldn't matter because we wouldn'a be getting the right counts. A hundred and fourteen geese is, is 
nothing. I know a boy that's getting twenty-thousand for it and he cuts silage a fortnight after us.

Seasonal cycles of production are bound up with the geese, with the counts taken at regular intervals by $\mathrm{SNH}$ and by comparison with neighbouring farmers, who are seen to gain far more income from geese despite being less disadvantaged than one might expect.

Bureaucratic systems related to other birds also influence these seasonal cycles. In early May the repetitive, rasping call of corncrakes begins to sound from beds of nettles and rushes. Unlike geese, corncrakes are not a pest to farmers, even though some complained about being kept up all night by their persistent calls. But conservationists are concerned about corncrakes, which have declined across Britain as agriculture intensifies. Research has shown that the breeding success of corncrakes is adversely affected by mowing regimes that trap fledglings in the centre of fields, preventing them from escaping without, terrifyingly for the birds, breaking cover. As such, conservationists instigated corncrake-friendly mowing techniques to avoid trapping young birds and, as part of conservation schemes, farmers also agreed to forego mowing until $1^{\text {st }}$ August. New seasonal patterns were thus imposed, sometimes to ridicule, not by the emergent ecological and meteorological patterns of the world but by bureaucratic plans that fix activity to specific dates. As one farmer told me:

Several years ago they used to tell the farmers they had to get in silage by 20th June because the nutritional value would tail off after that. Now they come here and tell us not to cut till 1st August.

The seasonal ecosystems of farming in Islay are thus made by a complex array of factors. Agricultural improvement encourages farmers to keep continental breeds of cattle that need to be kept indoors during the winter and fed on silage that the farmer produces from his fields. These silage fields are attractive to the geese that winter in Islay. The geese provide an income from conservation schemes but the farmer has to keep his livestock indoors much longer in the spring because of the loss of early bite. The farmer tries to harvest silage crops while the nutritional value of the grass is still high and before the autumn rains spoil them. But conservation schemes protecting corncrakes prevent him from cutting some until the beginning of August, when the calendrical dating of the scheme determines. The farmers, their livestock and crops, the geese and the corncrakes all help to make the seasons and are all 
bound up together in an uneasy being with in the taskscape of an Islay field. So too are the bureaucratic systems of conservation governance that extend the making of seasons outwards to include the wider nation that those systems purport to represent. Bureaucratic systems, which imagine nature and nation in their own way, thus come to be part of the lived emergence of seasonality even though those systems arise in terms of chronological timekeeping that is indifferent to the ongoing-ness of life on an Islay farm. The growth of grass and the feeding and breeding of animals, both wild and domestic, are not simply bound alongside one another in an ecology of growth and movement but in ways that draw in these wider 'structural' factors that might once have been theorised into the separate realm of society (cf. Vergunst et al, 2012). The growth of grass, the successful breeding of corncrakes, the fattening of geese and the in-wintering of cattle on an Islay farm are not articulations of society, in the form of policies and directives, and nature, in the form of plants, animals and ecosystems. They are the collective doings of humans and other species attending to and uneasily being with one another in more-than-human seasonalities.

\section{Migratory seasonalities}

The wider extensions of season-making are not just produced through governmental policies but can be revealed through scientific research (cf. Rodríguez-Giralt et al., 2014 pp.50-53). This has shown that corncrakes are threatened not just by farming activities in Britain but by the ravages of climate change and hunting where they migrate through and winter. Geese too are sometimes threatened by seasonal changes in their breeding grounds. Wet summers in the tundra can reduce the numbers wintering in Islay. The Greenland white-fronted geese that breed in west Greenland and migrate to Islay are reputedly declining because competitor species such as Canada geese have encroached into their breeding areas because of climate change.

Global seasonal extensions are also implicated in a famous British tradition: writing to The Times newspaper to report on hearing the first cuckoo of spring. Although it is several decades since The Times published such letters (McCarthy, 2009), it remains an example of a British propensity for noting, as well as noticing, the recurrent appearance of more-thanhuman phenomena during the year (cf. Macdonald, 2002). The science that emerged around this tendency - phenology - has more recently assumed a wider significance as a signifier of changes in seasonal patterns, potentially as a result of anthropogenic climate change. The 
arrival and departure of cuckoos is now monitored more closely than ever. Cuckoos have been declining and conservationists are keen to find out the causes and where they arise. Over recent years the British Trust for Ornithology has attached radio transmitters to numerous cuckoos around the UK. ${ }^{2}$ Their journeys across Europe and Africa are traced through transmitter readings and plotted on lines using Google Maps. Each named cuckoo has its own blog in which its readings are reported and their implications discussed. The most celebrated of the cuckoos is named Chris, after the presenter of Springwatch Chris Packham. Like Packham, Chris the cuckoo has proven a stern competitor and has migrated back from Africa over several years. In 2015, however, concerns over Chris grew. He left Britain as usual in July but a subsequent blog entry on $18^{\text {th }}$ August contained worrisome news:

We haven't received any good quality locations for Chris since 3 August, although poor quality signals do indicate that he left Italy shortly after this and was crossing the Mediterranean Sea on the 5 August.

The Po Valley in Italy is Chris's usual stopover site, however, the region is experiencing its worst drought in years, and given the short length of time our cuckoos have spent here this year, has presumably led to a shortage of caterpillars.

A series of poor signals from Chris's tag show that he has made it to the Tibesti mountains in Northern Chad by 8 August... He seems to have been here for around eight days which is very worrying as he normally crosses the desert in a day or two...

At this stage we are very concerned about him and, given the conditions in Italy, we fear that he may not have been able to take on the amount of food needed to prepare for, and successfully complete, the journey. ${ }^{3}$

The plight of Chris gathers the seasonalities of Britain together with seasonal and climatic changes elsewhere, in the drought stricken river valleys of Italy and the Saharan oases of Chad. Chris would have been heading to the tropics of central and west Africa to enjoy the seasonal bounty of the forests and take on food needed for the long journey back across the Sahara and Mediterranean. The seasonalities of weather patterns, plant growth and bird

\footnotetext{
${ }^{2}$ http://www.bto.org/science/migration/tracking-studies/cuckoo-tracking

${ }^{3} \mathrm{http}$ ///www.bto.org/science/migration/tracking-studies/cuckoo-tracking/chris
} 
migrations have the capacity to draw seemingly distinct categories, people, places and times together, a drawing together made remotely visible to scientists and citizens alike through technologies such as radio-tagging (Benson, 2010 p.190). The distinction of wild and domestic disappears for the grazing geese that link the tundra of Greenland to the improved grasslands of western Scotland. The cuckoos that heralded summer in medieval England still arrive, but their migratory life lines, traced on websites through radio transmitters, draw together a wider experience of the Anthropocene world. For someone sitting indoors and looking at a computer screen, the abrupt ending of those lines hints at anxieties (Whitehouse, 2015) of disrupted seasonality and climate change and the complexity of the problems facing both humans and cuckoos.

\section{Drawing together}

The gathering of life lines and places in narratives of migration is a relatively modern phenomenon in Britain. In the $19^{\text {th }}$ century many would have said that swallows hibernated in marshlands, barnacle geese formed from barnacles and cuckoos slept in hollow logs for the winter (Swainson, 1885). Another kind of seasonality emerges for those who trace the movements of Chris and other cuckoos via internet maps and blogs. It is not so much the intimate, acting together of being with or the partial world sharing of being alongside but a remote witnessing (cf. van Dooren \& Rose, 2016 pp.89-91): a care for species through indirect representations of their lives. Cuckoos and their seasonal movements are as likely to be perceived through lines on a map and the narratives these describe as through hearing a far-carrying two-note call just as the leaves are emerging on the trees. Those lines are a version of the lively stories from the dull edge of extinction that van Dooren (2014) calls for to foster concern for the violence the modern world can do to nonhumans and human relations to them (Cudworth, 2015). My own stories of more-than-human seasonalities in Britain are a drawing together of worlds that might readily be theorised, explained or defined as separate: the natural and the social, the phenomenological and the structural, the wild and the domestic, the outdoors and the indoors, the local, national and global. Seasonality is the doing of many beings and phenomena that pay no heed to those distinctions and, in their various ways, many in Britain still attend to these doings and their own place in relation to them. 


\section{References}

Benson, E., (2010). Wired wilderness: Technologies of tracking and the making of modern wildlife. Baltimore: John Hopkins University Press.

Cudworth, E. (2015). Killing animals: Sociology, species relations and institutionalized violence. The Sociological Review, 63, 1-18.

Davis, S., (2011). 'Britain an island again': Nature, the military and popular views of the British countryside, c.1930-1965. University of Cambridge: unpublished $\mathrm{PhD}$ thesis.

Evans-Pritchard, E., (1940). The Nuer: A description of the modes of livelihood and political institutions of a Nilotic people. Oxford: Clarendon.

Feld, S., (1982). Sound and sentiment: Birds, weeping, poetics, and song in Kaluli expression. Philadelphia: University of Pennsylvania Press.

Forth, G., (2004). Nage birds: Classification and symbolism among an eastern Indonesian people. London: Routledge.

Haraway, D., (2003). The companion species manifesto: Dogs, people, and significant otherness. Chicago: Prickly Paradigm Press.

Haraway, D., (2008). When species meet. Minneapolis: University of Minnesota Press. Harley, T., (2003). Nice weather for the time of year: the British obsession with the weather. In S. Strauss, \& B. Orlove (Eds.), Weather, climate, culture. Oxford: Berg.

Harris, M., (1998). The rhythm of life on the Amazon floodplain: Seasonality and sociality in a riverine village. Journal of the Royal Anthropological Institute, 4 (1), 65-82.

Harrison, S., (2004). Emotional climates: Ritual, seasonality and affective disorders. Journal of the Royal Anthropological Institute (N.S.) 10, 583-602.

Hurn, S. (2012). Humans and other animals: Cross-cultural perspectives on human-animal interactions. London: Pluto Press.

Ingold. T., (2000). The perception of the environment: Essays in livelihood, dwelling and skill. London: Routledge.

Ingold. T., (2011). Being alive: Essays on movement, knowledge and description. London: Routledge.

Kirksey, E., and Helmreich, S., (2010). The emergence of multispecies ethnography. Cultural Anthropology, 25 (4), 545-576.

Kohn, E., (2013). How forests think: Toward an anthropology beyond the human. Berkeley: University of California Press. 
Krause, F., (2013). Seasons as rhythms on the Kemi River in Finnish Lapland. Ethnos, 78 (1), $23-46$.

Latimer, J., (2013). Being alongside: Rethinking relations amongst different kinds. Theory, Culture and Society, 30 (7/8), 77-104.

Levin, T., (2006). Where rivers and mountains sing: Sound, music, and nomadism in Tuva and beyond. Bloomington: Indiana University Press.

Macdonald, H., (2002). "What makes you a scientist is the way you look at things":

Ornithology and the observer 1930-1955. Stud. Hist. Phil. Biol. \& Biomed. Sci., 33 (1), $53-$ 77.

Mauss, M., (1979 [1950]). Seasonal variations of the Eskimo: A study in social morphology. London: Routledge \& Kegan Paul.

McCarthy, M., (2009). Say goodbye to the cuckoo. London: John Murray.

Ogden, L., Hall, B., and Tanita, K., (2013). Animals, plants, people, and things: A review of multispecies ethnography. Environment and Society: Advances in Research 4, 5-24.

Olwig, K., (2005). Liminality, seasonality and landscape. Landscape Research, 30 (2), 259271.

Orlove, B., (2003). How people name seasons. In S. Strauss, \& B. Orlove (Eds.), Weather, climate, culture. Oxford: Berg.

Peggs, K. (2013). The 'animal-advocacy agenda': Exploring sociology for non-human animals. The Sociological Review, 61, 591-606.

Rodríguez-Giralt, I, Tirado, F. \& Tironi, M. (2014). Disasters as meshworks: Migratory birds and the enlivening of Doñana's toxic spill. The Sociological Review, 62:S1, 38-60.

Swainson, C., (1885). The folk lore and provincial names of British birds. United States: Kessinger.

van Dooren, T., (2014). Flight ways: Life and loss at the edge of extinction. New York:

Columbia University Press.

van Dooren, T. \& Rose, D. (2016). Lively ethnography: Storying animist worlds.

Environmental Humanities, 8 (1), 77-94.

Vergunst, J., Whitehouse, A., Ellison, N. and Arnason, A., (2012), Introduction: Landscapes beyond land. In A. Arnason, N. Ellison, J. Vergunst \& A. Whitehouse (Eds.), Landscapes beyond land: Routes, aesthetics, narratives. Oxford: Berghahn.

Whatmore, S., (2006). Materialist returns: Practising cultural geography in and for a morethan-human world. Cultural Geographies, 13 (4), 600-609. 
Whitehouse, A., (2004). Negotiating small differences: Conservation organisations and farming in Islay. University of St Andrews: unpublished $\mathrm{PhD}$ thesis.

Whitehouse, A., (2012). How the land should be: Narrating progress on farms in Islay, Scotland. In A. Arnason, N. Ellison, J. Vergunst \& A. Whitehouse (Eds.), Landscapes beyond land: Routes, aesthetics, narratives. Oxford: Berghahn.

Whitehouse, A., (2015). Listening to birds in the Anthropocene: the anxious semiotics of sound in a human-dominated world. Environmental Humanities, 6, 53-71.

Young, M., (1988). The metronomic society: Natural rhythms and human timetables. London: Thames and Hudson. 